Año LXXXI. urtea

$276-2020$

Enero-abril

Urtarrila-apirila

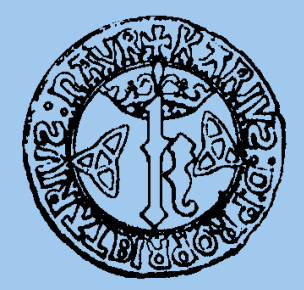

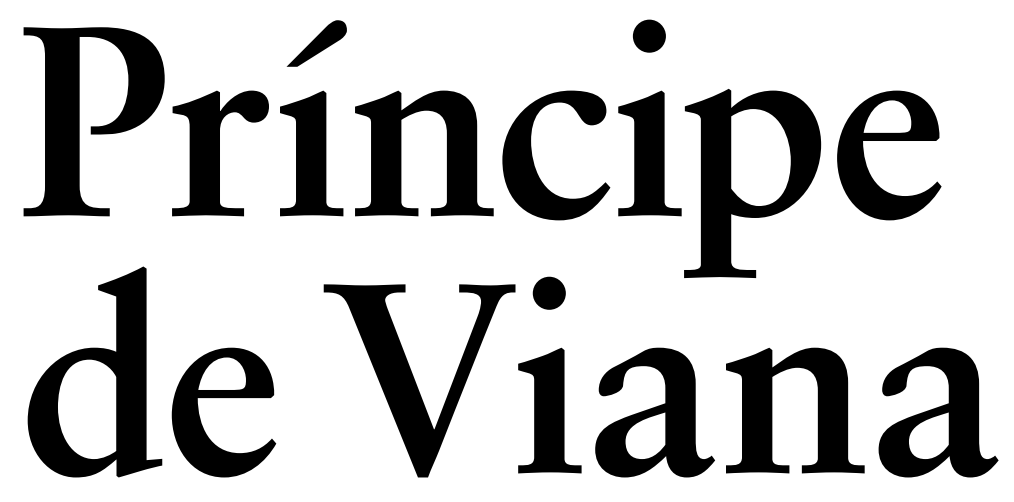

SEPARATA

Investigación y difusión del patrimonio cultural navarro en la Universidad de Navarra (2019)

Yolanda Cagigas Ocejo 


\section{Sumario / Aurkibidea}

\section{Príncipe de Viana}

Año LXXXI • n. ${ }^{\circ} 276$ • enero-abril de 2020

LXXXI. urtea $\cdot 276$. zk. 2020 ko urtarrila-apirila

\section{LITERATURA}

La realidad literaturizada y la ira contra la religión católica y el obispo de Pamplona en el «Libro segundo» de La familia de Errotacho, de Pío Baroja Miguel Ángel García de Juan

\section{HISTORIA}

La represión del protestantismo en el tribunal inquisitorial de Calahorra-Logroño (1550-1610)

Marcos Gómez García

Entre España y México, la libertad. El embajador Félix Gordón Ordás y su evocación de la figura del navarro Javier Mina en el marco de la guerra civil española

Un discurso inédito de Víctor Sainz de Robles en 1867

Emilio Cervantes Ruiz de la Torre

Política social y autogobierno en el núcleo de la conspiración carlista antirrepublicana

La botica del monasterio cisterciense de Santa María de La Oliva (Navarra) Juan Manuel Garde Garde

\section{DERECHO / ZUZENBIDEA}

Un debate sobre la Ley de 1841: Navascués, la Diputación, «El Mosquerino» y Ezquerra 


\section{Sumario / Aurkibidea}

\section{LOS TRABAJOS Y LOS DÍAS DEL AÑO 2019 / 2019ko LANAK ETA EGUNAK}

Tesis doctorales sobre temática navarra de ciencias humanas, sociales y jurídicas, leídas en 2019

(Según la Base de datos Teseo del Ministerio de Educación)

Medio siglo de Fontes Linguae Vasconum

Ekaitz Santazilia

Actividades en torno al cincuenta aniversario de la revista Cuadernos de

Etnología y Etnografía de Navarra

David Mariezkurrena

Autores y autoras navarras en castellano, año 2019

Mikel Zuza Viniegra

Nafar egileen euskarazko liburuak 2019an

Ángel Erro Jiménez

Viento a favor: talento y carácter. Navarra en la industria audiovisual (2019)

Marga Gutiérrez Díez

Tensión de rotura. Un panorama expositivo de 2019

Mireya Martín Larumbe

Hiriartea: crónica de un proyecto frustrado por una mala práctica en las políticas culturales

Arantza Santesteban

De escalas, tiempos y cultura: grado en Historia y Patrimonio por la UPNA

Fernando Mendiola Gonzalo, Miguel R. Wilhelmi

Investigación y difusión del patrimonio cultural navarro en la Universidad de

Navarra (2019)

Yolanda Cagigas Ocejo

Entrevista a Tomás Yerro Villanueva. Premio Príncipe de Viana de la Cultura 2019

Alicia Ezker Calvo

Si mi padre volviera, yo sería su escudero. Qué gran caballero era

Tomás Yerro. (Discurso)

Currículums

Analytic Summary

Normas para la presentación de originales / Idazlanak aurkezteko arauak /

Rules for the submission of originals

6 Príncipe de Viana (PV), 276, urtarrila-apirila, 2020 ISSN: 0032-8472 | ISSN-e: 2530-5824 | ISSN-L: 0032-8472 


\title{
Investigación y difusión del patrimonio cultural navarro en la Universidad de Navarra (2019)
}

\author{
Yolanda CAGIGAS OCEJO \\ Directora Archivo General Universidad de Navarra \\ ycagigas@unav.es
}

DOI: https://doi.org/10.35462/pv.276.17

\section{CHANTRIA PAMPILONENSE}

La Capilla de Música de la Catedral de Pamplona lleva tiempo emprendiendo proyectos para la conservación y divulgación de sus fondos musicales. Muestra de ello es la digitalización de sus fondos -75000 páginas-, la publicación en 2016 del Catálogo del Archivo de Música y que la Capilla haya publicado ya diecinueve CD preferentemente con música procedente de su Archivo $^{1}$, aun y todo, estos solo suponen una mínima parte del patrimonio conservado.

En 2017, el Instituto Cultura y Sociedad (ICS) de la Universidad de Navarra y la Capilla de Música de la Catedral acordaron llevar a cabo el proyecto Chantria Pampilonense. El proyecto consiste en transcribir, revisar y editar las obras más significativas de los fondos musicales que durante siglos el cabildo ha creado y conservado. Para Aurelio Sagaseta, chantre-maestro de la Capilla de Música, entre los trabajos necesarios para recuperar las partituras históricas se encuentran «la transcripción a notación moderna -sus claves antiguas son ilegibles para la gran mayoría de los intérpretes de nuestros días-, revisión musical, copia en distintos sistemas informáticos y edición impresa y digital del material recuperado» ${ }^{2}$.

1 Una descripción de cada grabación $c f r$. https://www.capillademusicapamplona.com/publicaciones/ discografia/ (consulta 06/05/2020).

2 https://institutoculturaysociedad.wordpress.com/2017/02/07/catedral-pamplona-patrimonio-musical-navarro-creatividad-y-herencia-cultural-chantria-pampilonense/ (consulta 06/05/2020). 
El objetivo del proyecto es «revitalizar esta importante dimensión de nuestra herencia cultural, poniéndolo a disposición de la sociedad y preparando el terreno para investigaciones futuras en el ámbito de la musicología ${ }^{3}$. Los miembros del equipo son: Aurelio Sagaseta, investigador principal, Rafael Zafra, coordinador, y Ángel Briz.

En 2017, la Capilla y la Universidad de Navarra publicaron el primer volumen del proyecto Chantria Pampilonense con el título Obras de maestros italianos en la $\mathrm{Ca}$ tedral de Pamplona ${ }^{4}$. El libro recoge tres obras inéditas de los compositores italianos Francesco Grassi y Girolamo Sertori y una grabación del concierto en el que dichas obras fueron interpretadas en la catedral por la Capilla de Música, la Coral de Cámara de Pamplona y la orquesta barroca Ensemble 5 .

En diciembre de 2018 se publicó el segundo volumen, con el título Motetes anónimos de la Catedral de Pamplona, que recoge una selección de veintiuna partituras. Según sus autores, estas breves composiciones musicales fueron compuestas en la primera mitad del siglo XVII y conforman un patrimonio musical inédito de indudable valor ${ }^{6}$. De nuevo la edición incluye una grabación de cinco de los motetes más representativos interpretados por la Capilla de Música.

En 2019 y como cierre de la primera fase del proyecto Chantria Pampilonense se publicó un tercer volumen donde se ha recuperado una singular versión del Requiem de Wolfgang Amadeus Mozart, del que se ha podido comprobar que no existen partituras similares en España.

La presentación tuvo lugar el 2 de noviembre durante la Misa de Difuntos, liturgia para la cual fue compuesta, y un concierto posterior ${ }^{7}$. La interpretación de las partituras, bajo la dirección de Aurelio Sagaseta, se llevó a cabo por la Orquesta Sinfónica de Navarra, el organista de la catedral Julián Ayesa, el coro de la Capilla de Música y cuatro solistas de fama internacional: Dorota Grzeskowiak (soprano), Liuboy Melnik (alto), José Luis Sola (tenor) y Silvano Baztán (barítono ${ }^{8}$. Una vez más, su grabación fue incluida en el libro.

3 https://institutoculturaysociedad.wordpress.com/2017/02/07/catedral-pamplona-patrimonio-musical-navarro-creatividad-y-herencia-cultural-chantria-pampilonense/ (consulta 06/05/2020).

$4 \mathrm{Cfr}$. https://www.capillademusicapamplona.com/noticias/publicacion-de-obras-de-maestros-italianos-en-la-catedral-de-pamplona/ (consulta 06/05/2020).

5 Cfr. Aurelio Sagaseta, https://www.unav.edu/web/instituto-cultura-y-sociedad/chantria-pampilonense/obras-de-2017 (consulta 06/05/2020).

6 Cfr. Natalia Rouzaut, "La Universidad de Navarra y la Catedral de Pamplona publican el segundo volumen de la colección "Chantria Pampilonense"». Noticia disponible en https://www.unav. edu/web/alumni/noticia-pestana/2019/01/14/la-universidad-de-navarra-y-la-catedral-de-pamplona-publican-el-segundo-volumen-de-la-coleccion- 'chantria-pampilonense'? articleId=20458573 (consulta 06/05/2020).

7 Se puede disfrutar del concierto en el canal de YouTube de la Capilla de Música, cfr. https://www. youtube.com/watch?v=A2Sbn6Z0oXM\&feature=youtu.be (consulta 06/05/2020).

8 Cfr. https://www.capillademusicapamplona.com/noticias/requiem-de-mozart-manuscrito-unico-catedral-pamplona/ (consulta 06/05/2020). 
Los tres volúmenes de la colección han sido publicados conjuntamente en la Editorial Universidad de Navarra -EUNSA- y la alemana Reichenberger con el propósito de dar cauce y visibilidad internacional a proyectos similares en torno a la música de las catedrales europeas. En palabras del coordinador del proyecto, Rafael Zafra, «supone sacar a la luz joyas del relevante patrimonio que custodia la Catedral con el fin de hacerlas vivas y que se puedan interpretar en cualquier parte del mundo» ${ }^{9}$.

\section{SANTA CRIZ DE ESLAVA}

Ubicado en la Comarca de Sangüesa, el yacimiento Santa Criz de Eslava conserva los restos del que fuera el foro y la necrópolis de la ciudad. Fue descubierto en 1917 por el sacerdote Juan Castrillo y desde mediados de los años 90 ha sido objeto de excavaciones arqueológicas continuadas y lideradas por el equipo de Tx. Mateo, P. Sáez y R. Armendáriz. Actualmente, y gracias a un convenio de colaboración suscrito entre el Ayuntamiento de Eslava y la Facultad de Filosofía y Letras de la Universidad de Navarra, se organizan visitas guiadas para grupos ${ }^{10}$.

El libro Santa Criz de Eslava, reflejos de Roma en territorio vascón es una obra que surge como catálogo de una exposición que lleva el mismo título, y ha sido escrito por Javier Andreu -director del Diploma en Arqueología de la Facultad de Filosofía y Letras de la Universidad de Navarra-, Inmaculada Delage y Luis Romero -doctorandos del centro académico- y Txaro Mateo, arqueóloga de Santa Criz. Pablo Serrano, experto en fotogrametría digital, ha participado en el proyecto con la realización de modelos en 3D de algunos de los materiales hallados, que pueden verse en el Museo Virtual ${ }^{11}$.

Editado por el Servicio de Patrimonio Histórico del Gobierno de Navarra, el libro se estructura en torno a los distintos materiales arqueológicos hallados en la ciudad: inscripciones, estatuaria, cerámica, vidrio, moneda, metales y huesos. Para Javier Andreu «es la primera en Navarra que reúne lo más representativo de la cultura material de una ciudad romana de los Vascones antiguos; el primer espacio que permitirá acercarse a la influencia cultural de Roma en las poblaciones locales: Santa Criz se convirtió en una imagen en miniatura de la propia Roma», y "permitirá una aproximación al mejor y

9 Isabel Solana, «Una colección de libros revive obras religiosas inéditas de los fondos musicales de la Catedral de Pamplona». Noticia disponible en https:/www.unav.edu/web/vida-universitaria/detallenoticiapestania/2018/10/09/una-coleccion-de-libros-revive-obras-religiosas-ineditas-de-los-fondos-musicales-de-la-catedral-de-pamplona?articleId=19460695 (consulta 06/05/2020).

10 Cfr. http://www.santacrizdeeslava.com (consulta 06/05/2020).

11 Cfr. María M. Orbegozo, La exposición «Santa Criz de Eslava, reflejos de Roma en territorio vascón» propicia la edición de un libro en torno a esta muestra, Noticia disponible en https:/www.unav. edu/web/vida-universitaria/detalle-noticia-pestana/2019/07/04/la-exposicion-\%E2\%80\%9Csanta-criz-de-eslava-reflejos-de-roma-en-territorio-vascon $\%$ E2\% 80\%9D-propicia-la-edicion-de-unlibro-en-torno-a-esta-muestra? articleId=22201403 (consulta 06/05/2020) 
más completo conjunto de estatuaria romana que hay en Navarra y a uno de los repertorios de inscripciones más representativos de la Comunidad Foral» ${ }^{12}$.

Patrocinado por el Gobierno de Navarra, el proyecto ha contado también con la colaboración de la Fundación Caja Navarra y la asociación Cederna Garalur. La muestra ha sido posible gracias a los fondos Feader y Leader.

\section{UNA COLECCIÓN DE CASCANTE}

La obra Versos e imágenes. Gozos en Navarra y en una colección de Cascante, escrita por Ricardo Fernández Gracia, cuenta con 397 páginas y fue editada por el Servicio de Publicaciones de la Universidad de Navarra y patrocinada por la Fundación Fuentes Dutor con la colaboración de la Asociación Vicus. Además cuenta con una versión digital consultable gratuitamente ${ }^{13}$.

El contenido del libro se ha organizado en tres partes: aspectos generales relativos a este tipo de impresos y sus autores, el comentario de los gozos navarros localizados hasta el momento, y los gozos de la colección de Cascante, en la que se explica su origen, catalogación y comentarios para una mejor comprensión y contextualización.

Tal y como ha explicado el autor, «el proyecto surgió por los innegables valores iconográficos, devocionales y antropológicos de una colección de gozos que don Alfonso Fernández donó a la Basílica de Nuestra Señora del Romero». La monografía recopila y analiza cerca de un centenar de gozos, "una parte del patrimonio heredado de nuestros mayores a través de cuyos versos muchas personas que no sabían ni leer ni escribir aprendían vidas de santos, prodigios de imágenes marianas, sus historias y leyendas, en definitiva, signos de identidad de pueblos, villas y comarcas» ${ }^{14}$.

\section{LÉXICO NAVARRO EN LOS SIGLOS XVI Y XVII}

Cristina Tabernero y Jesús M. Usunáriz, miembros del Grupo de Investigación Siglo de Oro (GRISO) de la Universidad de Navarra, publicaron el Diccionario de injurias de

12 María M. Orbegozo, Presentación del libro e inauguración de la exposición «Santa Criz de Eslava, reflejos de Roma en territorio vascón», Noticia disponible en https:/www.unav.edu/web/ facultad-de-filosofia-y-letras/detalle-noticia/2019/06/28/presentacion-del-libro-e-inauguracion-de-la-exposicion-\%E2\% 80\%9Csanta-criz-de-eslava-reflejos-de-roma-en-territorio-vascon\%E2\%80\%9D/-/asset_publisher/4G6p/content/2019_06_28_fyl_noticia_presentacion_libro_ santa_criz/10174 (consulta 06/05/2020).

13 Disponible en el Depósito Académico Digital de la Universidad de Navarra-DADUN- en http://hdl. handle.net/10171/58523 (consulta 06/05/2020).

14 María M. Orbegozo, Un libro recopila y estudia una colección de gozos navarros, Noticia disponible en https://www.unav.edu/web/facultad-de-filosofia-y-letras/detalle-noticia-pestana/2019/12/12/un-libro-recopila-y-estudia-una-coleccion-de-gozos-navarros?articleId=24667379 (consulta 06/05/2020). 
los siglos XVI y XVII, editado por Reichenberger. Este diccionario es el resultado del análisis de cerca de mil quinientos procesos judiciales sobre injurias de los siglos XVI y XVII, conservados en el Archivo Real y General de Navarra ${ }^{15}$.

La obra comprende más de mil términos y expresiones, acompañados de la definición, información gráfica, etimológica y gramatical de 8200 contextos de uso, y de más de mil ochocientos testimonios documentales. El conjunto constituye un reflejo de lo que pudo ser la oralidad de los hablantes del pasado y de sus valores culturales. Se trata de una aportación a la historia del léxico y a la historia social del Siglo de Oro español ${ }^{16}$.

\section{EUSKAL HIZKUNTZA ETA KULTUR KATEDRA}

El 19 de octubre, la Cátedra de Lengua y Cultura Vasca / Euskal Hizkuntza eta Kultur Katedra organizó un ciclo de conferencias en la localidad de Ochagavía bajo el título: «Federico Garralda y el euskera salacenco / Ez dugu izaundu alkea». La jornada giró en torno a la presentación del libro El renacimiento cultural vasco en el valle del Salazar. Federico Garralda Argonz y su entorno (1881-1929) / Euskal berpizkundea Zaraitzuko ibarrean. Federiko Garralda Argontz eta haren ingurua (1881-1929), editado de manera bilingüe por Lamiñarra. El evento contó con la intervención de los autores del libro: Eduardo Garralda, descendiente del escritor; Alejandro Pulido, historiador estudioso de los euskalkis navarros e Iñigo Auzmendi, experto en euskera salacenco.

La obra ofrece una aproximación inédita a la contribución de Garralda al renacimiento cultural vasco. Sus artículos publicados entre 1915 y 1927, mayoritariamente en la revista Euskal Esnalea, han sido en las últimas décadas una de las fuentes fundamentales para el estudio y conservación del euskera de Salazar, y constituyen un rico legado etnográfico de los más variados aspectos de la cultura local ${ }^{17}$.

15 La obra también fue presentada en el Archivo Real y General de Navarra: $c f r$. https://grisounav.wordpress.com/2019/10/14/cristina-tabernero-y-jesus-m-usunariz-presentan-su-diccionario-de-injurias-de-los-siglos-Xvi-y-xvii-en-el-archivo-real-y-general-de-navarra/; en Viena, $c f r$. https:/grisounav.wordpress.com/2019/11/04/presentado-en-viena-el-diccionario-de-injuriasde-los-siglos-xvi-y-xvii-de-cristina-tabernero-y-jesus-m-usunariz/; en Moscu, https:/grisounav. wordpress.com/2019/10/04/presentado-en-moscu-el-diccionario-de-injurias-de-los-siglos-xvi-yxvii-de-cristina-tabernero-y-jesus-m-usunariz/; y en Münster (Alemania), cfr. https://grisounav. wordpress.com/2019/09/27/9098/ (consulta 06/05/2020.)

16 Cfr. "Cristina Tabernero y Jesús M. Usunáriz, del GRISO, publican un "Diccionario de injurias de los siglos XVI y XVII”», noticia disponible en https://www.unav.edu/web/facultad-de-filosofia-y-letras/detalle-noticia/2019/07/01/cristina-tabernero-y-jesus-m-usunariz-del-griso-publican-un-\%E2\% 80\%9Cdiccionario-de-injurias-de-los-siglos-xvi-y-xvii\%E2\% 80\%9D/-/asset_publisher/4G6p/content/2019_07_01_fyl_noticia_diccionario_injurias/10174 (consulta 06/05/2020).

17 «La Cátedra de Lengua y Cultura Vasca de la Universidad organiza en Ochagavía un ciclo sobre Federico Garralda y el euskera salacenco», Noticia disponible en https://www.unav.edu/web/facultad-de-filosofia-y-letras/detalle-noticia/2019/10/15/la-catedra-de-lengua-y-cultura-vasca-de-la-universidad-organiza-en-ochagavia-un-ciclo-sobre-federico-garralda-y-el-euskera-salacenco/-/asset_ publisher/4G6p/content/2019_10_15_fyl_noticia_federico_garralda/10174 (consulta 06/05/2020). 
También intervino un grupo de estudiosos en cuestiones filológicas y literarias relativas al euskalki y expertos en temas etnográficos propios de la cultura local, en consonancia con el doble valor del legado de Garralda. Asier Barandiaran -profesor de la UPV/EHU- contextualizó la obra de Garralda en el marco de la literatura vasca en Navarra de entre siglos; Iñaki Camino - profesor de la UPV/EHU- trazó un completo panorama sobre "El vasco salacenco en la historia del euskara»; Juan Karlos Lopez-Mugartza -profesor de la UPNA- habló sobre «Los nombres de las casas de Salazar»; el escritor salacenco e impulsor de la revista Mendixut, Xabier Díaz Esarte, puso fin al ciclo de conferencias con una exposición acerca del «Euskara Zaraitzun azken hamarkadetan» en la que describió los avances y logros de la recuperación del euskera (batua) en el valle, gracias especialmente a la labor desempeñada desde la escuela. El coro salacenco Zaraitzun Kantuz, que reúne a personas del valle con el objetivo de recuperar viejas canciones en el euskera local, clausuró la sesión de la mañana con un pequeño concierto. Por la tarde, los asistentes realizaron una visita guiada a la ermita de Nuestra Señora de Muskilda.

Al tiempo que Barandiaran puso en marcha en la Universidad de Navarra el Curso Monográfico de Etnología Vasca (1964-1979), dio inicio a la investigación etnológica con la creación del Grupo Etniker, adscrito a la Cátedra de Lengua y Cultura Vasca. En el año 2019, la Cátedra organizó dos actividades junto a Etniker ${ }^{18}$. La primera, los II Encuentros de Etnografía, se celebró el 19 de septiembre en la sede del Civican. El objetivo era homenajear a José María Satrustegi, euskalzale y etnógrafo navarro, en el 50 aniversario de dos de las más importantes iniciativas culturales en las que estuvo implicado, las revistas Fontes Linguae Vasconum y Cuadernos de Etnología y Etnografía de Navarra. La jornada comenzó con la sesión «Miradas sobre la obra etnográfica de José María Satrustegi», en la que intervinieron tres profesores de la Universidad de Navarra: Jesús M. Usunáriz analizó los ritos del embarazo, el parto y el matrimonio, tomando como referencia un estudio de Satrustegi sobre estas cuestiones; Naiara Ardanaz, subdirectora de la Katedra y coordinadora del evento, ofreció una aproximación a la figura del Olentzero a partir de las aportaciones de reconocidos estudiosos, como el Padre Donostia, Barandiaran, Pío Baroja, Azkue, Caro Baroja y Satrustegi; Ana Belén Martínez contextualizó los dos romances estudiados por Satrustegi, el del amante relegado y el de la doncella guerrera, en una amplia tradición también presente en otras literaturas.

El segundo bloque de la jornada, dedicado a las «Iniciativas culturales de un euskaltzale navarro", congregó en una mesa redonda, moderada por David Mariezkurrena -director de la revista Cuadernos de Etnología y Etnografía de Navarra-, a dos de los estudiosos más cercanos a la persona y obra de Satrustegi. Andres Iñigo le recordó como un verdadero referente del estudio y fomento del euskera en la segunda mitad del siglo $\mathrm{xx}$, con más de un millar de artículos, muchos de ellos referidos a onomástica, y también como un infatigable trabajador, entusiasta y enérgico, y como un gran comunicador y embajador de la lengua vasca. La faceta etnográfica de Satrustegi fue puesta de relieve por Anton

18 Más información sobre Etniker, cfr. https://www.etniker.com/etniker/ (consulta 06/05/2020). 
Erkoreka, director del Museo Vasco de Historia de la Medicina, quien destacó la intensa labor realizada por el homenajeado en las décadas de los 40, 50 y 60, sus aportaciones al estudio de la mitología vasca y su proyecto de un museo etnográfico a partir de su colección personal. Los Encuentros finalizaron con la actuación musical de Ruper Ordorika, quien interpretó una selección de canciones tradicionales vascas y navarras ${ }^{19}$.

La Cátedra de Lengua y Cultura Vasca, también junto a Etniker, organizó un ciclo de conferencias sobre «El patrimonio cultural de Tafalla». Patrocinado por el Gobierno de Navarra, se celebró el 8 de junio en el Centro Cultural de la localidad, y acudieron más de sesenta personas. La primera conferencia corrió a cargo de Alberto Magán, músico y profesor, quien abordó las tradiciones y leyendas del patrón de Tafalla, san Sebastián, desde los orígenes de la devoción al santo, hasta su proclamación como patrón de la ciudad. A continuación, Javier Torralba impartió la ponencia «Diez años de "Tafalla a pie": el blog que redescubre la historia viva de los términos de Tafalla». El ciclo fue clausurado con una sesión a cargo de David Mariezkurena e Iñigo Aguerri, miembro del grupo de folk Mielotxin y autor del libro Los Pajes de Tafalla. Pioneros de la jota navarra. Durante su intervención, Aguerri puso de relieve la primera aportación a la jota navarra, a finales del siglo XIX, y animó a conservar esta tradición. Además, improvisó con el acordeón una pieza musical. Por la tarde, los asistentes realizaron una visita a los caseríos de El Saso. La jornada finalizó con una presentación a cargo de Mauricio Olite, de "Oinez Basoa», un proyecto pionero de bosque monitorizado con el objetivo de mejorar el medioambiente de la zona y de educar y concienciar a los más jóvenes en la preservación de la naturaleza ${ }^{20}$.

El curso "El cantar de Ursúa. Mujer, lengua y tradición musical en las dos Navarras» reunió a cerca de setenta personas y se desarrolló en el Archivo Real y General de Navarra y en dos de los escenarios relacionados con la leyenda: el solar originario de los Lizarazu-Santa María en Hélette (Baja Navarra) y el valle de Baztan. El cantar de Urtsua, probablemente de origen medieval, narra una trágica historia sucedida en el valle de Baztan. Seiscientos años después, todavía son muchos los interrogantes que plantea, como si está basada en un hecho real, si se cantó en euskera en la corte de Olite o si refleja la situación de la mujer en esa época.

La primera jornada se inauguró con una interpretación del cantar de Ursúa, a cargo de Beltxaren Taldea. A continuación, Txema Hidalgo, autor de Nafar Aire Zaharretan,

19 Cfr. La Cátedra de Lengua y Cultura Vasca de la Universidad y Etniker Navarra celebran los II Encuentros de Etnografía, noticia disponible en https://www.unav.edu/web/facultad-de-filosofia-y-letras/detalle-noticia/2019/10/01/la-catedra-de-lengua-y-cultura-vasca-de-la-universidad-y-etniker-navarra-celebran-los-ii-encuentros-de-etnografia/-/asset_publisher/4G6p/content/2019_10_01_fyl_noticia_encuentros_etnografia/10174 (consulta 06/05/2020).

20 Cfr. María M. Orbegozo, «Más de 60 personas participan en una jornada sobre el patrimonio cultural de Tafalla», Noticia disponible en https://www.unav.edu/web/catedra-de-lengua-cultura-vasca/noticias/detalle-noticia/2019/07/17/mas-de-60-personas-participan-en-una-jornada-sobre-el-patrimonio-cultural-de-tafalla/-/asset_publisher/pXsp2NHohyjO/content/2019_07_17_ fyl_noticia_acercar_patrimonio_cultural/10174 (consulta 06/05/2020). 
expuso los rasgos principales de los cantares vascos que han llegado hasta nosotros y que en un número muy elevado proceden de Navarra. Asimismo, subrayó los indicios que permiten suponer que la historia narrada en este cantar se apoya en un hecho real, y expuso algunas hipótesis sobre sus protagonistas. Por su parte, Ana Isabel Ugalde, de la UPV/EHU, impartió una sesión sobre el papel de la mujer en la creación e interpretación musical, desde la antigüedad, con las plañideras, hasta el siglo XX, con las bertsolaris.

La segunda jornada del curso contó con la intervención de Luis San Martín, del Conservatorio Superior de Música de Navarra, quien repasó la historia musical de Navarra, con especial énfasis en las figuras de los trovadores, juglares y ministriles de la corte, un ámbito en el que se movió el juglar llamado Ursúa, quien sirvió a Carlos III en Olite, a principios del siglo XV. Peio J. Monteano, del Archivo Real y General de Navarra, abordó la hipótesis de que el euskera fuera una lengua hablada no solo por los vecinos de la Montaña de Navarra, sino utilizada en la Ribera del Ebro y también en la corte de Olite, bajo el reinado de Carlos III, por lo que, a su juicio, El cantar de Ursúa pudo ser interpretado en euskera ante el monarca.

La tercera jornada se desarrolló en la Baja Navarra. En el palacio de Santa María de Hélette, Ana Zabalza -profesora de la Universidad de Navarra y directora de la actividad- ofreció una explicación de la vinculación del solar con el palacio de Ursúa. A continuación, se clausuró el curso con una nueva interpretación del cantar de Ursúa ${ }^{21}$.

\section{CÁTEDRA DE PATRIMONIO Y ARTE NAVARRO}

Entre otras actividades, la Cátedra de Patrimonio y Arte Navarro viene organizando desde 2005 ciclos de conferencias, patrocinadas por el Gobierno de Navarra y abiertas a todos los públicos. A lo largo del año 2019 fueron un total de veinticuatro las que organizaron, agrupadas en siete ciclos, impartidas durante los meses de mayo a octubre ${ }^{22}$.

Con el primer ciclo -«La obra en su contexto»-, más de doscientas personas pudieron conocer algo más de cerca algunas de las obras de arte más emblemáticas que se conservan en Pamplona, como el órgano de la iglesia de Santo Domingo, de la mano de Raúl del Toro -Conservatorio Pablo Sarasate-; la parroquia de San Cernin, a cargo de

21 Cfr. «La Cátedra de Lengua y Cultura Vasca clausura el curso "El cantar de Ursúa. Mujer, lengua y tradición musical en las dos Navarras”». Noticia disponible en https://www.unav.edu/web/ facultad-de-filosofia-y-letras/detalle-noticia/2019/06/25/la-catedra-de-lengua-y-cultura-vascaclausura-el-curso-\%E2\% 80\%9Cel-cantar-de-ursua-mujer-lengua-y-tradicion-musical-en-las-dosnavarras\%E2\%80\%9D/-/asset_publisher/4G6p/content/2019_06_25_fyl_noticia_katedra_cantar_ursua/10174 (consulta 06/05/2020).

22 Cfr. https://www.unav.edu/web/catedra-patrimonio/actividades/ciclos-y-conferencias/2019 (consulta 06/05/2020). 
Clara Fernández Ladreda -Universidad de Navarra-; y los retablos del convento de las Recoletas, con Ricardo Fernández Gracia, director de la Cátedra de Patrimonio y Arte Navarro. En la última sesión del ciclo los asistentes realizaron un recorrido guiado por Javier Azanza -profesor de la Universidad de Navarra- por esculturas del centro de la ciudad como el monumento al Encierro, la estatua de Carlos III, el monumento a los Fueros o la estatua de San Francisco.

«Torres y campanas» fue el título del segundo ciclo que tuvo lugar en el Palacio del Condestable. Ricardo Fernández Gracia destacó que «además de ser bienes culturales tangibles, poseen también gran parte de los secretos que guarda nuestro patrimonio inmaterial» ${ }^{23}$. La primera sesión giró en torno a las tipologías de las torres-campanario y su evolución desde la Edad Media hasta nuestros días, y fue impartida por Javier Azanza, bajo el título "Centinelas de ladrillo y sillar: una mirada a las torres campanario navarras». Por su parte, Miguel Bañales -archivero de la empresa Scriptum y de la Asociación de Campaneros de Navarra- trató sobre «Las campanas: testigos de la historia local».

Sobre «Patrimonio y clausura» fue el tercer ciclo, celebrado en el mes de agosto, donde Ricardo Fernández Gracia se ocupó del tema de las «Clausuras en Navarra: más allá del patrimonio material», y María Josefa Tarifa -Universidad de Zaragoza- de «Monjas que dejaron huella en el patrimonio del monasterio de Tulebras». También en el mes de agosto, en Cascante, se desarrolló el ciclo que llevaba el nombre de esta localidad. En él, el director de la Cátedra ilustró a los asistentes sobre los «Símbolos y atributos en la construcción de las imágenes: ejemplos en Cascante» y Carlos Carrasco -doctor en Historia del Arte- sobre «La arquitectura civil en la Ribera de Navarra».

«El patrimonio cultural en el valle de Roncal» fue abordado por otro de los ciclos, celebrado en el municipio del mismo nombre. José Ignacio Riezu Boj-Universidad de Navarra- se ocupó de los «Secretos del patrimonio roncalés: piedras», y Pablo Orduna Portús -Universidad Internacional de La Rioja- del "patrimonio material e inmaterial en el paisaje cultural roncalés».

Durante tres días, en septiembre, tuvo lugar el ciclo «Viana en su VIII centenario: cultura y patrimonio». Allí se trató de "Historia de las historias de Viana», pronunciada por Román Felones; "Construir una "catedral" en la frontera. Arquitecturas góticas de Viana», por Carlos Martínez Álava; "Música y músicos: la capilla de música de Santa María de Viana, siglos XVI-XIX», por Juan Cruz Labeaga Mendiola; «Arquitectura y poder: ciudad y familias», por Pilar Andueza; «La capilla de San Juan del Ramo y las pinturas de Paret», por José Javier Azanza; «La portada de Santa María, obra

23 María Orbegozo, «La Cátedra de Patrimonio y Arte Navarro organiza el ciclo de conferencias “Torres y campanas”", Noticia disponible en https://www.unav.edu/web/facultad-de-filosofia-y-letras/detalle-noticia/2019/06/11/la-catedra-de-patrimonio-y-arte-navarro-organiza-el-ciclo-de-conferencias-\%E2\% 80\%9Ctorres-y-campanas\%E2\%80\%9D/-/asset_publisher/4G6p/content/2019_06_11_fyl_noticia_torres_campanas/10174 (consulta 06/05/2020). 
sobresaliente del Renacimiento hispano", por María Josefa Tarifa; "Artes decorativas en Viana», por Ignacio Miguéliz; y «Viana: singularidades históricas y sociales», por Félix Cariñanos.

El tema del «Patrimonio hidráulico en Navarra» se abordó en el último ciclo, celebrado en octubre, con las siguientes conferencias y ponentes: «El legado de la ingeniería romana. El sueño del agua», Carmen Jusué Simonena -UNED Pamplona-; «Tipos y usos hidráulicos en Navarra durante la Edad Media», David Alegría -doctor en Historia-; «El abastecimiento de agua en Pamplona en el contexto de la Ilustración», José Luis Molins -antiguo archivero municipal de Pamplona-; «El agua en Navarra en 2019», Francisco Galán Soraluce, ingeniero de caminos.

La Cátedra de Patrimonio y Arte Navarro comenzó en 2019 una nueva actividad, Descubre Navarra con Diario de Navarra. En el mes de octubre se fue a Viana, y la visita fue ilustrada por Ricardo Fernández Gracia, comentando «Un templo magnífico de la mano de destacados maestros y mecenas»; Román Felones abordó el tema de «Un conjunto amurallado en una encrucijada entre Castilla y Navarra»; M. ${ }^{a}$ Josefa Tarifa comentó «Arquitectura y humanismo: la portada de Santa María, un hito del Renacimiento en España»; y por último, Pilar Andueza trató sobre "Arte y poder local: el esplendor urbano en los siglos del Barroco» ${ }^{24}$. En noviembre se acudió a Leire, y allí se dieron cita Clara Fernández-Ladreda para hablar de «Leire como cuna del románico»; Juan Manuel Apesteguía -abad del monasterio de Leire- que explicó la orden de San Benito; y Luis Javier Fortún -archivero del Parlamento, académico correspondiente de la Historia, que realizó tu tesis doctoral sobre Leire- hizo una síntesis de «Los doce siglos de vida monástica en Leire» ${ }^{25}$. La última sesión tuvo lugar en la catedral de Pamplona, para hablar sobre la Navidad. Como ponentes acudieron Carlos-Esteban Ayerra Sola -deán de Pamplona-; Ricardo Fernández Gracia, cuyo tema fue «Poniendo imágenes a la Navidad en la catedral»; Alejandro Aranda Ruiz -doctor en Historia del Arte- explicó «La liturgia y ceremonial» de estas fiestas; y Manuel Casado Velarde -Universidad de Navarra- habló sobre «Los poetas cantan la Navidad ${ }^{26}$.

Por último, cabe mencionar también la colección Patrimonio e identidad, publicada en el Diario de Navarra y escrita por Ricardo Fernández Gracia. Si en el año 2018 el director de la Cátedra de Patrimonio y Arte Navarro publicó catorce artículos de dicha colección, en 2019 fueron dieciséis, en concreto: «Evocaciones de la Epifanía», «Imágenes de las Cortes de Navarra», «Una serie grabada de los reyes pamploneses y navarros», «La imagen municipal: arquitectura, heráldica y patronatos», «La imagen municipal: Protocolo y ceremonial», «Lo sagrado: santoral y grandes advocaciones marianas», «Navarra como tema alegórico y simbólico», tres artículos de «Buriles y pinceles al servicio de los navarros ilustres», «Orígenes e hipótesis sobre el patrimonio

24 Cfr. «Viana, una ciudad monumento», Diario de Navarra, 06/10/2019.

25 Cfr. «Leire, el Monasterio de Navarra», Diario de Navarra, 03/11/2019.

26 Cfr. «Navidad en la catedral de Pamplona», Diario de Navarra, 01/12/2019. 
mueble de Leire», «Libros excelentes con destinos singulares», «Entre lo insólito y lo legendario: visiones y maravillosismo", "Medio de comunicación de antaño: los bandos», «Escenas de crueldad infantil en el arte navarro»y «La Navidad en la pintura del siglo $\mathrm{XVI»}{ }^{27}$.

27 Dichos artículos fueron publicados en el Diario de Navarra los días 20/12/2019, 06/12/2019, $15 / 11 / 2019$, 01/11/2019, 18/10/2019, 04/10/2019, 21/06/2019, 07/06/2019, 17/05/2019, 05/04/2019, 15/03/2019, 01/03/2019, 15/02/2019, 01/02/2019, 18/01/2019, 04/01/2019. 